\title{
A Breathless Dilemma: Myelomatous Pleural Effusion
}

\section{Niroshan Thiruchelvam ${ }^{1 *}$, Mykola Onyshchenko², Jaskirat Randhawa ${ }^{3}$ and Narendrakumar Alappan ${ }^{1}$}

${ }^{1}$ Department of Pulmonary Medicine, Respiratory Institute, Cleveland Clinic, Cleveland, $\mathrm{OH}, \mathrm{USA}$

${ }^{2}$ Department of Hematology and Oncology, UCLA, Los Angeles, CA, USA

${ }^{3}$ Department of Hematology and Oncology, University of Cincinnati, Cincinnati OH, USA

\section{Introduction}

Pleural effusions in haematological malignancies are not uncommon. However, myelomatous pleural effusions (MPE) which are effusions directly related to infiltration of the pleura by plasma cells, are extremely rare. Herein we report a case of pleural effusion in patient with multiple myeloma.

\section{Presentation}

A 66 year old Caucasian woman presented to the emergency department with three week history of progressive shortness of breath and fatigue. Her past medical history was significant for IgA light chain multiple myeloma and hyperparathyroidism for which she had underwent Para-thyroidectomy. She had undergone multiple chemotherapy regimens including bortezomib, carfilzomib, Cytoxan, thalidomide and lenalilomide with failure to respond. At presentation, she was afebrile, heart rate of 120 beats $/ \mathrm{min}$, respiratory rate of 38 breaths $/ \mathrm{min}$, oxygen saturation of $95 \%$ on $55 \%$ venti mask and blood pressure of $120 / 80$ $\mathrm{mmHg}$.

Her physical examination was remarkable for stony dullness and reduced breath sounds on the right side of the chest. Initial laboratory investigations were significant for white cell count of $1 \times 103$ cells $/ \mathrm{mm}^{3}$, hemoglobin $6.0 \mathrm{~g} / \mathrm{dl}$, and creatinine of $8.12 \mathrm{mg} / \mathrm{dl}$ and BUN $100 \mathrm{mg} / \mathrm{dl}$. Chest X-ray demonstrated complete opacification of the right lung with mediastinal shift to the left (Figure 1). She underwent ultrasound guided thoracentesis and $1.7 \mathrm{~L}$ of serous fluid was removed. Pleural fluid analysis revealed white cells of $575 / \mathrm{uL}$ with $56 \%$ atypical cells, exudative fluid as per Lights criteria.

On detailed cytological analysis, these atypical cells were single enlarged cells with eccentric nuclei, and were immunoreactive to CD138 supporting plasma cell differentiation (Figure 2). Hence, the diagnosis made as large right true MPE. She was treated with haemodialysis and plasmapheresis for renal failure due to myeloma kidney. Recurrent pleural fluid accumulation was treated with pigtail catheter and this relieved her shortness of breath.

\section{Discussion}

Pleural effusions of true hematologic origin are rare occasional findings at some hematologic diseases. It was described in patient with chronic lymphocytic leukemia and was confirmed by lymphoma cells without Richter transformation at a high concentration [1]. Primary effusion lymphoma as a rare type of non-Hodgkin lymphoma was observed in herpes virus-8-positive but interestingly immunocompetent HIV negative patient [2]. Extramedullary hematopoietic effusion was described by Sekiguchi et al. [3] in 54-year-old man with follicular lymphoma; pleural effusion aspirate and a biopsied specimen obtained via thoracoscopy revealed megakaryocytes and immature myeloid cells in addition to lymphoma cells. Pleural effusion was observed in Multicentric Castleman's disease, a polyclonal lymphoproliferative disorder that manifests as marked hyper- $\gamma$-globulinemia, severe inflammation, anemia, and thrombocytosis [4]. Yamada et al. reported pleural effusion as initial presentation of MALT lymphoma and was associated with elevated CA125 [5].

True myelomatous pleural effusions (MPE) are very uncommon, with fewer than 100 cases reported in literature [6-12]. The diagnosis is usually confirmed by cytologic identification of malignant plasma cells and high levels of a monoclonal protein in the pleural fluid and histological study of pleural biopsy $[13,14]$ At the time of diagnosis of MPE, patients also frequently have elevated serum $\beta 2$-microglobulin, anemia, elevated serum lactate dehydrogenase, and elevated creatinine levels. Of various subtypes the incidence of MPE has been found remarkably high with IgD myeloma subtype [13]. However, other case studies suggest that majority of MPE take place in patients with the most abundant, IgG myeloma. Case reviews also show that MPE occurs equally among both genders, is typically hemorrhagic and occurs more commonly on the left [15-17].

Role of flow cytometry of pleural fluid has also been studied as a potentially useful and simple tool diagnosis (positive for CD56, CD38 and CD138, while negative for CD19), however it is not a standard method for diagnosis [18]. Elevated ADA activity in the pleural fluid

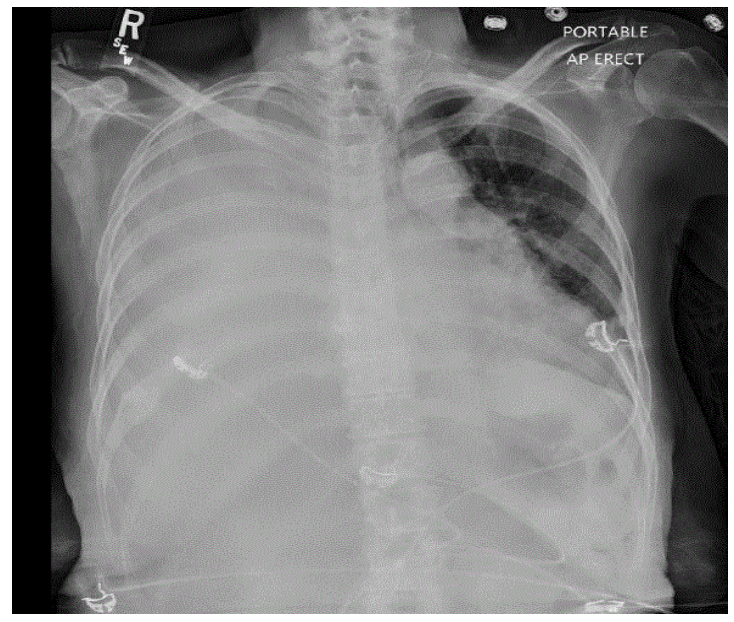

Figure 1: Myelomatous pleural effusion, AP portable chest X-ray

*Corresponding author: Niroshan Thiruchelvam, MD, Department of Pulmonary Medicine, Respiratory Institute, Cleveland Clinic, Cleveland, OH, USA, Tel: (216) 904 1965; E-mail: thirucn@ccf.org

Received November 23, 2015; Accepted November 30, 2015; Published December 04, 2015

Citation: Thiruchelvam N, Onyshchenko M, Randhawa J, Alappan N (2015) A Breathless Dilemma: Myelomatous Pleural Effusion. J Clin Respir Dis Care 1: 101 doi: 10.4172/ JCRDC.1000101

Copyright: (c) 2015 Thiruchelvam N, et al. This is an open-access article distributed under the terms of the Creative Commons Attribution License, which permits unrestricted use, distribution, and reproduction in any medium, provided the original author and source are credited. 


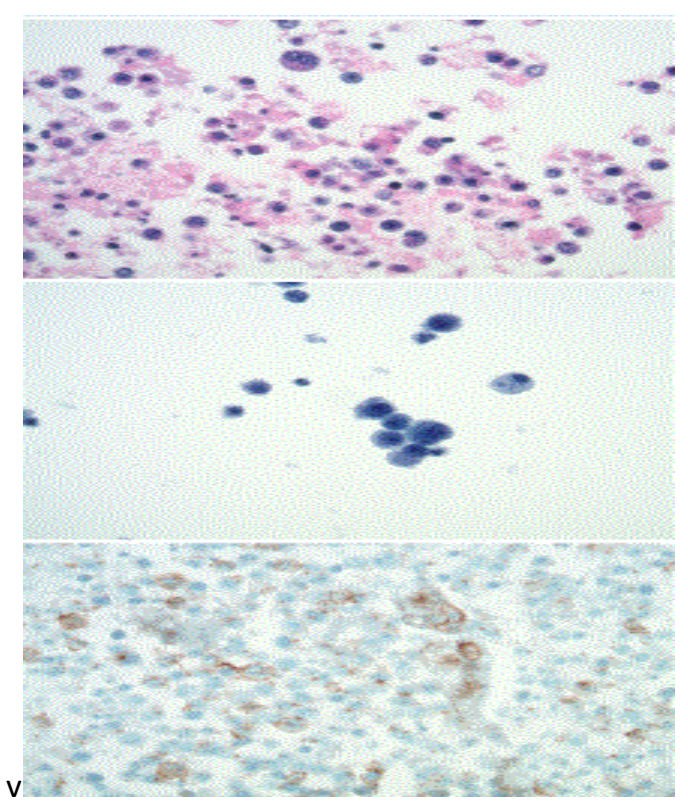

Figure 2: Cytological studies of myelomatous pleural effusion. The pictures of cell block (top) and thinprep (middle) show a discohesive population of single cells with eccentric nuclei, prominent nucleoli and a nuclear hoff; (bottom) CD138 immunostaining, marker of plasma cells.

(which can exceed the upper limits for tuberculous pleural effusions) could be helpful for detecting MPE at early stage [13].

\section{Management}

Various chemotherapies used in treatment include vincristine, adriamycin, cyclophosphamide, bortezomib with/without steroids combination. Low dose bortezomib has shown partial response in malignant pleural effusion in few cases; however this was followed by early relapse later in disease course [19]. Intrapleural injections of different chemotherapeutic agents like adriamycin and interferon were proposed $[20,21]$. Unfortunately, the outcome of these patients has not been favorable and they are usually found resistant to multiple chemotherapies. The median survival can vary between months to years. Timely etiological diagnosis and appropriate treatment is pivotal in overall prognosis in these patients.

\section{References}

1. Nakazawa H, Nishina S, Mimura Y, Kawakami T, Senoo Y, et al. (2014) Tumor lysis syndrome in a chronic lymphocytic leukemia patient with pleural effusion after oral fludarabine and cyclophosphamide therapy. Int J Hematol 99.

2. Yagi H, Ozaki S, Sekimoto E, Shibata H, Shigekiyo T, et al. (2013) Rapidly progressive $\mathrm{AL}$ amyloidosis in a patient with relapsed multiple myeloma after achieving a complete response to tandem autologous PBSCT. Rinsho Ketsueki 54: $2171-2176$

3. Sekiguchi N, Noto S, Wagatsuma M, Midorikawa K, Tezuka S, et al. (2013)
Extramedullary hematopoietic pleural effusion accompanied by follicular lymphoma. Intern Med 52: 2801-2804.

4. Masaki Y, Nakajima A, Iwao H, Kurose N, Sato T, et al. (2013) Japanese variant of multicentric castleman's disease associated with serositis and thrombocytopenia--a report of two cases: is TAFRO syndrome (CastlemanKojima disease) a distinct clinicopathological entity? J Clin Exp Hematop 53 79-85.

5. Yamada A, Sugimoto K, Matuno K, Tutui M, Yahata Y, et al. (2013) Primary pleural of mucosa-associated lymphoid tissue lymphoma. Rinsho Ketsueki 54: 463-467.

6. Agarwal A, Singla S, Bansal M, Nair B (2012) Bilateral Pleural Effusions due to Pulmonary Amyloidosis as the Presenting Manifestation of Multiple Myeloma. Mediterr J Hematol Infect Dis 4: e2012010.

7. Al-Farsi K, Al-Haddabi I, Al-Riyami N, Al-Sukaiti R, Al-Kindi S (2011) Myelomatous Pleural Effusion: Case report and review of the literature. Sultan Qaboos Univ Med J 11: 259-264.

8. Alshati MH, Kumar R, Kannan S (2013) Dyspnea, massive effusion and lytic rib lesion as initial presentation of multiple myeloma in a young man. Can Respir J 20: 253-255

9. Ghoshal AG, Sarkar S, Majumder A, Chakrabarti S (2010) Unilateral massive pleural effusion: a presentation of unsuspected multiple myeloma. Indian J Hematol Blood Transfus 26: 62-64.

10. Mehta AA, Venkatakrishnan R, Jose W, Palaniappan M, Pavithran K (2010) Multiple myeloma presenting as eosinophilic pleural effusion. Asia Pac J Clin Oncol 6: 256-259.

11. Oudart JB, Maquart FX, Semouma O, Lauer M, Arthuis-Demoulin P, et al. (2012) Pleural effusion in a patient with multiple myeloma. Clin Chem 58: 672674

12. Xu XL, Shen YH, Shen Q, Zhou JY (2013) A case of bilateral pleural effusion as the first sign of multiple myeloma. Eur J Med Res 18: 7.

13. Cho YU, Chi HS, Park CJ, Jang S, Seo EJ, et al. (2011) Myelomatous pleural effusion: a case series in a single institution and literature review. Korean J Lab Med 31: 225-230.

14. Rodríguez JN, Pereira A, Martínez JC, Conde J, Pujol E (1994) Pleural effusion in multiple myeloma. Chest 105: 622-624.

15. Kamble R, Wilson CS, Fassas A, Desikan R, Siegel DS, et al. (2005) Malignan pleural effusion of multiple myeloma: prognostic factors and outcome. Leuk Lymphoma 46: 1137-1142.

16. Kim YJ, Kim SJ, Min K, Kim HY, Kim HJ, et al. (2008) Multiple myeloma with myelomatous pleural effusion: a case report and review of the literature. Acta Haematol 120: 108-111.

17. Huang TC, Chao TY (2010) Myelomatous pleural effusion. QJM 103: 705-706

18. Keklik M, Sivgin S, Pala C, Eroglu C, Akyol G, et al. (2012) Flow cytometry method as a diagnostic tool for pleural fluid involvement in a patient with multiple myeloma. Mediterr J Hematol Infect Dis 4: e2012063.

19. Sekiguchi Y, Shirane S, Imai H, Sugimoto K, Wakabayashi M, et al. (2012) Response to low-dose bortezomib in plasma cell leukemia patients with malignant pleural effusion and ascites: a case report and a review of the literature. Intern Med 51: 1393-1398.

20. Iannitto E, Scaglione R, Musso M, Abbadessa V, Licata G (1988) Intrapleura adriamycin in treatment of myelomatous pleural effusion: a case report Haematologica 73: 325-326.

21. Makino S, Yamahara S, Nagake Y, Kamura J (1992) Bence-Jones myeloma with pleural effusion: response to alpha-interferon and combined chemotherapy. Intern Med 31(5): 617-621. 